\title{
A rare case of primary hepatic solitary fibrous tumor associated with pregnancy
}

\author{
Gabriel Acosta-Gonzalez ${ }^{1}$, Margaret Cho $^{2}$, Robert Rogers ${ }^{1}$, Fernando Mariz ${ }^{3}$, Leon Pachter ${ }^{1}$, Antonio Neto*1 \\ ${ }^{1}$ Department of Pathology, New York University School of Medicine, New York, United States \\ ${ }^{2}$ Department of Pathology, Yale University School of Medicine, New Haven, United States \\ ${ }^{3}$ Department of Obstetrics and Gynecology, The University of Toledo, Toledo, United States
}

Received: April 18, 2016

DOI: $10.5430 /$ crcp.v3n3p66
Accepted: June 11, $2016 \quad$ Online Published: June 29, 2016

URL: http://dx.doi.org/10.5430/crcp.v3n3p66

\begin{abstract}
Purpose: To describe a case of histologically and immunohistochemically confirmed primary hepatic solitary fibrous tumor (SFT) associated with pregnancy.

Case report: A 40-year-old Caucasian woman G3P1021 with history of oral contraceptive use and no other known significant past medical history delivered via C-section in November of 2012. Two months post delivery, she noted that her abdomen did not decrease in size and sought medical attention. As part of the work-up, an abdominal MRI revealed a $15.9 \mathrm{~cm}$ mass centered in segment $4 \mathrm{~b}$ of the liver with extension into segments 5 and 8 within the right lobe. In addition, an exophytic component extending inferiorly from the liver into the right mid abdomen was noted. The patient underwent an uncomplicated hepatic segmentectomy with cholecystectomy. Grossly, the tumor consisted of a firm tan-white well-circumscribed and partially encapsulated mass. Histologically, the tumor was composed of cytologically bland spindle cells with a patternless architecture with hypocellular and hypercellular areas embedded within a collagenous fibrous stroma with occasional dilated branching thin-walled blood vessels. The tumor showed no infiltrative margins or necrosis and a mitotic count of 1/10HPF. Tumor cells were strongly and diffusely positive for CD34, BCL-2, and vimentin; weakly positive for STAT6 (nuclear distribution); and focally positive for CD99 and $\beta$-Catenin. In addition, estrogen and progesterone receptors (ER and PR) were also performed and showed positive staining. The diagnosis of SFT was confirmed. To date, 36 months post-resection, our patient has been followed with imaging, showing no evidence of residual or recurrent disease.

Conclusions: Primary hepatic SFT is exceedingly rare and even more so in association with pregnancy. Positive immunohistochemical staining of tumor cells for progesterone and estrogen receptors may indicate hormonal stimulation as a driver of neoplastic cell proliferation.
\end{abstract}

Key Words: Solitary fibrous tumor, Hepatic solitary fibrous tumor, Liver, Pregnancy

\section{INTRODUCTION}

Solitary fibrous tumor (SFT) is a rare mesenchymal neoplasm that most commonly involves the pleura. ${ }^{[1]}$ SFTs may also occur in the peritoneum, mesentery, pericardium, orbit, upper respiratory tract, and meninges. ${ }^{[2-6]}$ The liver is a rare primary site for SFTs with less than 50 cases reported in the English literature. ${ }^{[7-17]}$ Although most cases of SFTs are benign, there have been cases of SFTs with malignant features and metastasis. ${ }^{[18,19]}$ Both clinical and radiographic features are not entirely specific and cannot exclude malignancy. Sur-

*Correspondence: Antonio Neto; Email: antonio.galvaoneto@nyumc.org; Address: Department of Pathology, New York University School of Medicine, NY 10016, New York, United States. 
gical resection with clean resection margins is the preferred therapeutic option. ${ }^{[20]}$ Interestingly, only four cases of SFT associated with pregnancy have been reported, with one other case occurring in the liver. ${ }^{[21-24]}$ We present a rare case of benign primary SFT occurring in the liver in association with pregnancy with ER and PR positive receptors.

\section{Case presentation}

A 40-year-old Caucasian woman G3P1021 with history of oral contraceptive use until January 2011 with no other known significant past medical history delivered via Csection in November of 2012. Two months post delivery; the patient sought medical attention as she noted that her abdomen did not go down. Abdominal MRI revealed a $15.9 \mathrm{~cm}$ mass centered in segment $4 \mathrm{~b}$ of the liver with extension into segments 5 and 8 within the right lobe. An exophytic component extended inferiorly from the liver into the right mid abdomen. The mass exhibited T1-hypointensity, T2-hyperintensity, intermediate ADC, and small arterial vessels coursing through the lesion without other evidence of arterial hypervascularity. The differential diagnosis of hepatocellular carcinoma, inflammatory adenoma, or SFT was raised radiographically. The patient was brought to surgery and an intraoperative frozen section was performed, which revealed a spindle cell lesion. The patient underwent an uncomplicated hepatic segmentectomy, with local aggressive resection of the tumor with clean surgical margins obtained, with cholecystectomy.

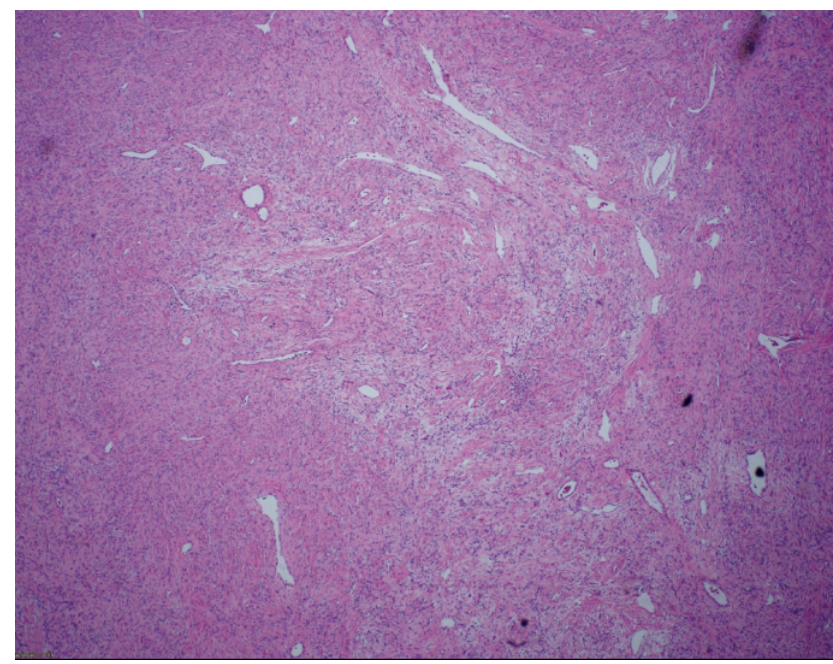

Figure 1. H\&E $40 \times$. Low power view of the tumor showing a proliferation of spindle cells with characteristic patternless architecture with alternating hypocellular and hypercellular areas. No areas of necrosis are present.

Gross examination revealed a $17.7 \mathrm{~cm} \times 13 \mathrm{~cm} \times 13 \mathrm{~cm}$. partial hepatectomy specimen with a weight of 1,392 grams and Published by Sciedu Press intact smooth liver capsule. A tan-white well-circumscribed firm tumor $(15.9 \mathrm{~cm} \times 12.4 \mathrm{~cm} \times 12.1 \mathrm{~cm})$ was identified in the liver parenchyma and located $0.7 \mathrm{~cm}$ from the nearest resection margin. No hemorrhage, necrosis or cystic degeneration was grossly identified within the tumor. The uninvolved liver parenchyma showed no micro/macronodular cirrhosis or any other lesions. The intact gallbladder $(7.6 \mathrm{~cm}$ in length and $4.3 \mathrm{~cm}$ in maximum diameter) had a $0.3 \mathrm{~cm}$ lymph node attached to the unremarkable cystic duct. The hepatic surface was rough. The peritoneal surface was smooth and glistening, and the mucosa was granular. The wall thickness averaged $0.2 \mathrm{~cm}$ with no other lesions seen.

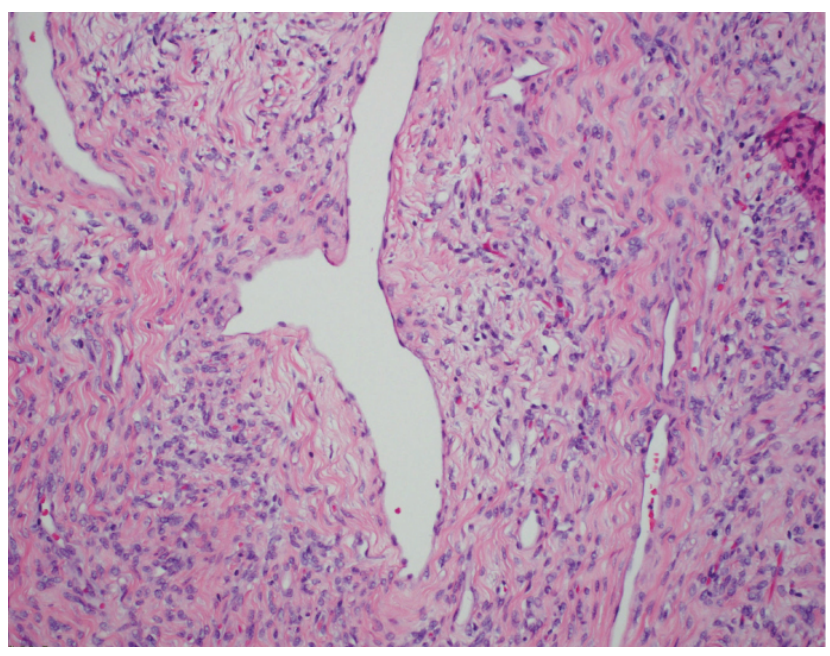

Figure 2. H\&E 200×. Medium power view of the neoplasm showing cytologically bland spindle cells without atypia or pleomorphism, embedded within a collagenized stroma. There is no discernible mitotic activity. Note the characteristic hemangiopericytoma-like thin-walled branching blood vessel in the center.

Microscopically, the tumor showed patternless architecture with both hypocellular and hypercellular areas on a background of collagenized fibrous stroma. Tumoral cells were spindled and bland, without pleomorphism, bizarre mitotic figures or necrosis/apoptosis (see Figures 1-2). Some of the cells were grouped together forming intersecting fascicles, more so in the hypercellular areas. Vessels showed the socalled hemangiopericytic features in a few sections (see Figure 2). The morphology, along with positive immunostains for CD34, vimentin, BCL-2 (all strongly positive), STAT6 (weak and diffuse nuclear expression) and focal positivity for CD99, $\beta$-Catenin, ER, and PR, were consistent with the diagnosis of SFT of the liver (see Figures 3-4; CD34, BCL-2, ER, $\mathrm{PR}$, vimentin, $\beta$-Catenin, ki-67). EMA, Hep-Par1, AE1/AE3, ALK-1, desmin, S-100, SMA, CD117 (C-KIT) and Factor-8 were negative. The panMelan-A stain was equivocal. The tumor lacked an infiltrative pattern or necrosis, and was pre- 
dominantly hypocellular with a mitotic count of 1/10HPF, at most. The ki-67 showed very low proliferative index $(<10 \%)$. No lymphovascular, large vessel, or perineural invasion were identified. Surgical resection margins were negative.
The nonneoplastic liver parenchyma was predominantly unremarkable. The trichrome and reticulin stains showed no fibrosis or cirrhosis, and the iron and D-PAS stains were negative. The gallbladder was without significant abnormality.

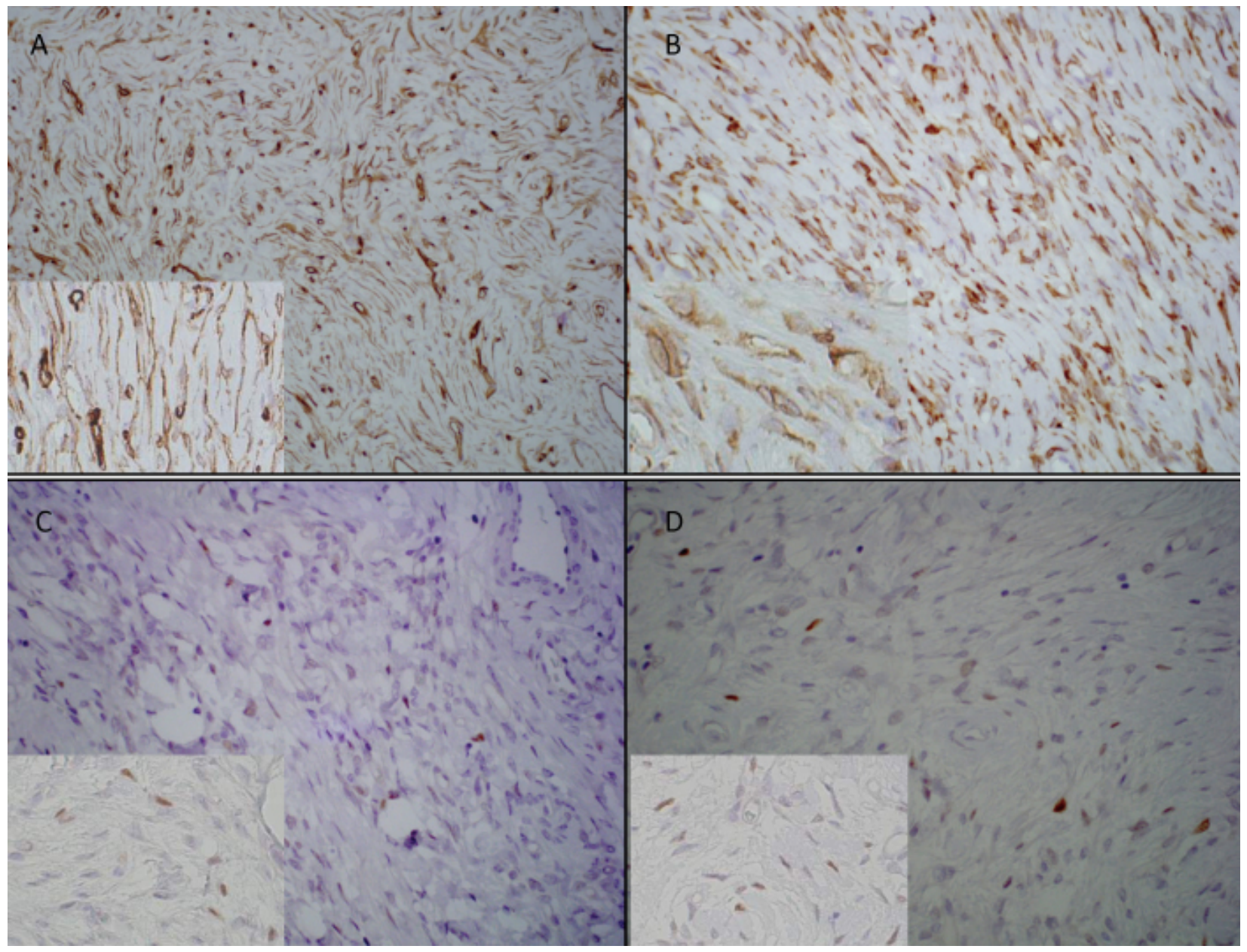

Figure 3. Immunohistochemical stains showing tumor cells strong and diffusely positive for CD34 (A) and BCL-2 (B) and focally positive for PR (C) ER (D)

\section{Discussion}

Solitary fibrous tumors, which were first described by Klemperer and Rabin in 1931, ${ }^{[25]}$ are defined by the WHO Classification as ubiquitous mesenchymal tumors of probable fibroblastic type, which show a prominent hemangiopericytomalike branching vascular pattern. ${ }^{[26]}$ In the past, many SFTs were termed hemangiopericytomas, which are now classified as a variant of SFT by the WHO. ${ }^{[27]}$ SFTs are primarily thoracic cavity neoplasms, mainly occurring in the pleura. Extrapleural SFTs have been observed in middle-aged adults with a median age of 50 years, with no sex predilection. ${ }^{[26]}$ Clinical symptoms, including hypoglycemia, may occur secondary to production of insulin-like growth factor. ${ }^{[28]}$

The liver is a rare primary site for SFTs with less than 50 cases reported in the English literature. ${ }^{[7-19]}$ Patient characteristics associated with hepatic SFTs include a mean age of 55 years at presentation, female sex predilection (2:1), and an average tumor size of $17 \mathrm{~cm}^{[7]}$ Although the vast majority of hepatic SFTs behave in a benign fashion, their unpredictable behavior must be emphasized. Four of the reported cases in the literature displayed aggressive behavior with distant metastases, with one of the cases having a latency period of 6 years between initial diagnosis and advent of metastatic disease. ${ }^{[7-12]}$ Metastatic primary hepatic SFTs are associated with larger tumor size (median size of $28 \mathrm{~cm}$ ). and higher mitotic activity. ${ }^{[9]}$ However not all large tumors behave aggressively and no relationship between morphologic features and poor behavior were identified. ${ }^{[9]}$ These findings underscore the importance of long-term follow-up 
in all affected patients, due to the absence of reliable features that would allow for prognostic or risk stratification in this

patient population.

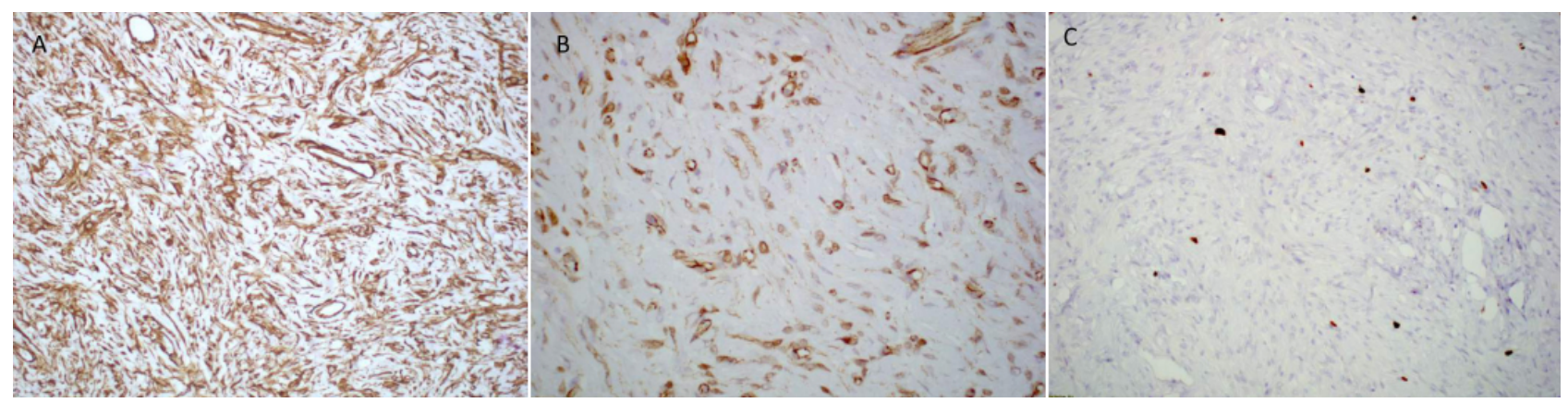

Figure 4. Immunohistochemical stains showing tumor cells to be diffusely positive for Vimentin (A), focally positive for $\beta$-Catenin (B) with occasional nuclear staining, and a very low proliferation rate with ki-67 (C)

The association of SFTs with pregnancy is even rarer. Our literature search reveals only four cases of SFT associated with pregnancy occurring in the liver, adrenal gland, orbit, and retroperitoneum. ${ }^{[21-24]}$ The role of pregnancy in the growth of tumors, in general, is not fully understood. However, it is known that hormonal conditions may favor the growth of soft tissue tumors. ${ }^{[22]}$ Pregnancy has been associated with rapid growth of uterine leiomyomas during early gestation and increased incidence of abdominal wall desmoid tumors. ${ }^{[29,30]}$ It is probable that the rise of sex steroids, along with a multitude of placental, fetal, and maternal hormones, play a collective role in the growth of tumors during gestation. This is supported by the reported cases of SFT of the orbit and adrenal gland associated with pregnancy. Both of these cases showed rapid tumor growth during the gestation, with the SFT of the adrenal gland increasing $3 \mathrm{~cm}$ in size during the last trimester of pregnancy. ${ }^{[22,23]}$ Of the four reported SFTs associated with pregnancy, immunohistochemistry for ER and PR was performed in only the adrenal gland specimen, which showed focal positive staining for PR while negative for ER. ${ }^{[22]}$ Of note, one study evaluated the expression of steroid receptors (AR, ER, and PR) in thirty-two pleural SFTs. Eight out of thirty-two expressed PR (25\%), while none expressed ER or AR, suggesting that progesterone may have a role in the growth of SFTs. ${ }^{[31]}$ Our case demonstrated positive staining (focal) for ER and PR (see Figure 3), suggesting a role for hormonal stimulation as a driver of tumor cell proliferation in SFTs in keeping with what has been described in the literature.

Histologically, typical SFTs show a patternless architecture characterized by a combination of alternating hypocellular and hypercellular areas separated by thick bands of hyalinized, somewhat keloidal, collagen and branching hemangiopericytoma- like vessels. Myxoid change, areas of fibrosis and interstitial mast cells are commonly observed. Mitoses are generally scarce. SFTs may show morphologic features of malignancy, such as hypercellularity, cytological atypia, tumor necrosis, and numerous mitoses ( $>4$ mitoses per 10 high-power fields) along with infiltrative margins. Immunophenotype in SFTs include positivity for STAT6 (restricted nuclear expression), CD34 (90\% to 95\% of cases), and CD99 (70\%). Recent studies, using whole exome sequencing, identified a recurrent and pathognomonic NAB2STAT6 gene fusion in $100 \%$ of tested SFTs. ${ }^{[32]}$ Immunohistochemistry for STAT6 has been shown to be an excellent surrogate marker for the fusion protein, with a recent study showing staining limited to the nucleus in $100 \%$ of SFTs tested (total of 49 cases). ${ }^{[33]}$ Restricted nuclear expression of STAT6 was seen regardless of morphologic pattern or malignant features, highlighting the high sensitivity and specificity of this ancillary study. The same study tested 159 other tumors considered in the differential diagnosis of SFTs, with only four cases showing weak STAT6 nuclear expression. ${ }^{[33]}$ Tumor cells are also variably positive for epithelial membrane antigen (20\% to 35\%), BCL2, and smooth muscle actin. Notably, SFTs can behave unpredictably with high mitotic counts being the best predictor of poor outcome. About $10 \%$ to $15 \%$ behave aggressively, and a long-term follow-up is necessary to exclude recurrence, progression or metastases. ${ }^{[26]}$ Our patient's tumor showed no morphologic features of malignancy and to date, she has been followed with imaging; showing no evidence of residual or recurrent disease.

The differential diagnosis of SFT of the liver includes other mesenchymal neoplasms found in this location; including smooth muscle tumors, peripheral nerve sheath tumors, inflammatory myofibroblastic tumor, desmoid tumors, sclerosed, hemangioma, gastrointestinal stromal tumor, fibrosar- 
coma, and dedifferentiated liposarcomas and synovial sarcomas. The histologic appearance of the tumor, along with the results of a comprehensive immunohistochemical panel (positive for STAT6, CD34, BCL-2, vimentin, CD99 and negative for SMA, CD117, ALK-1, S-100, AE1/AE3, $\beta$-Catenin, desmin) is key for the diagnosis of SFT and to rule out other diagnostic possibilities. Of note, although nuclear STAT6 immunoreactivity is considered a highly sensitive and specific marker of SFTs and can help clinch the diagnosis in difficult cases, $20 \%$ of cases can show heterogeneous staining with zonal attenuation. ${ }^{[33]}$ This probably reflects differences in tissue fixation and ischemia, and was most commonly seen in big resection specimens. Thus, pre-analytical variables can affect the performance of the STAT6 immunostain and tumor samples from large resection specimens should promptly be placed in fixative to ensure optimal results. ${ }^{[33]}$
In summary, primary SFTs of the liver are rare and the association with pregnancy is even rarer. Awareness of the association of SFTs with pregnancy is important, as the hormonal milieu of gestation may promote or initiate their growth. SFTs must be differentiated from other entities with different biological behaviors and treatments. The prognosis of SFT is favorable; however aggressive surgical removal of the tumor with clear margins of resection is the mainstay of therapy. More studies are necessary to determine the association of this neoplasm with pregnancy, along with identification of molecular and clinical features that could better predict its biologic behavior. Until then, long-term follow-up of these patients is paramount, due to the unpredictable behavior of these neoplasms.

\section{CONFlicts OF InTEREST Disclosure}

The authors declare no conflict of interest.

\section{REFERENCES}

[1] Briselli M, Mark EJ, Dickersin GR. Solitary fibrous tumor of the pleura: Eight new cases and review of 360 cases in the literature. Cancer. 1981; 47: 2678-89. PMid: 7260861. http://dx.doi.org/10.1002/1097-0142(19810601) 47: 11<2678: : AID-CNCR2820471126>3.0.CO;2-9

[2] Young RH, Clement PB, McCaughey WTE. Solitary fibrous tumors ('fibrous mesotheliomas') of the peritoneum: A report of three cases and a review of the literature. Arch Pathol Lab Med. 1990; 114: 493-5. PMid: 2334258.

[3] Segawa D, Yoshizu H, Haga Y, et al. Successful operation for solitary fibrous tumor of the epicardium. J Thorac Cardiovasc Surg. 1995; 109: 1246-8. PMid: 7776690. http://dx.doi.org/10.1016/S 0022-5223(95) 70210-5

[4] Dorfman DM, To K, Dickersin GR, et al. Solitary fibrous tumor of the orbit. Am J Surg Pathol. 1994; 18: 281-7. PMid: 8116796. http://dx.doi.org/10.1097/00000478-199403000-00008

[5] Safneck JR, Alguacil-Garcia A, Dort JC, et al. Solitary fibrous tumor: Report of two new locations in the upper respiratory tract. J Laryngol Otol. 1993; 107: 252-6. PMid: 8509708. http://dx.doi .org/10. 1017/S0022215100122777

[6] Carneiro SS, Scheithauer BW, Nascimento AG, et al. Solitary fibrous tumor of the meninges: A lesion distinct from fibrous meningioma. Am J Clin Pathol. 1996; 106: 217-24. PMid: 8712177. http://dx.doi.org/10.1093/ajcp/106.2.217

[7] Feng LH, Dong H, Zhu YY, et al. An update on primary hepatic solitary fibrous tumor: An examination of the clinical and pathological features of four case studies and a literature review. PathologyResearch and Practice. 2015; 211: 911-7. http://dx.doi.org/1 $0.1016 / j \cdot$ prp. 2015.09 .004

[8] Beltran M. Solitary fibrous tumor of the liver: a review of the current knowledge and report of a new case. J Gastrointest Canc. 2015; 46 : 333-42. http://dx.doi.org/10.1007/s12029-015-9769-1

[9] Makino Y, Miyazaki M, Shigekawa M, et al. Solitary fibrous tumor of the liver from development to resection. Intern Med. 2015; 54 765-70. http://dx.doi.org/10.2169/internalmedicine. 54 .3053
[10] Debs T, Kassir R, Ben Amor I, et al. Solitary fibrous tumor of the liver: Report of two cases and review of the literature. International Journal of Surgery. 2014; 12: 1291-4. http://dx . doi .org/10.10 $16 /$ j.ijsu. 2014.10.037

[11] Liu Q, Liu J, Chen W, et al. Primary solitary fibrous tumors of the liver: a case report and literature review. Diagnostic Pathology. 2013; 8: 195. http://dx.doi.org/10.1186/1746-1596-8-195

[12] Teixeira F, de Freitas Perina AL, de Oliveira Mendes G, et al. Fibrous solitary tumor of the liver. J Gastrointest Canc. 2014; 45: S216-7. http://dx.doi.org/10.1007/s12029-014-9635-6

[13] Changku J, Shaohua S, Zhicheng Z, et al. Solitary fibrous tumor of the liver: Retrospective study of reported cases. Cancer Invest. 2006; 24: 132-5. PMid: 16537181. http://dx.doi.org/10.1080/073 57900500524348

[14] Vennarecci G, Ettorre GM, Giovannelli L, et al. Solitary fibrous tumor of the liver. J Hepatobiliary Pancreat Surg. 2005; 12: 3414. PMid: 16133706. http://dx.doi.org/10.1007/s00534-0 05-0993-0

[15] Ji Y, Fan J, Xu Y, et al. Solitary fibrous tumor of the liver. Hepatobiliary Pancreat Dis Int. 2006; 5: 151-3. PMid: 16481304.

[16] Guglielmi A, Frameglia M, Iuzzolino P, et al. Solitary fibrous tumor of the liver with CD 34 positivity and hypoglycemia. J Hepatobiliary Pancreat Surg. 1998; 5: 212-6. PMid: 9745091. http: //dx.doi.org/10.1007/s005340050036

[17] Patra S, Vij M, Venugopal K, et al. Hepatic solitary fibrous tumor: report of a rare case. Indian Journal of Pathology and Microbiology. 2012; 55(2): 236-8. PMid: 22771653. http://dx.doi.org/10. 4103/0377-4929.97892

[18] Peng L, Liu Y, Ai Y, et al. Skull base metastases from a malignant solitary fibrous tumor of the liver. A case report and literature review. Diagn Pathol. 2011; 6: 127. PMid: 22192457. http://dx.doi.org/10.1186/1746-1596-6-127

[19] Jakob M, Schneider M, Hoeller I, et al. Malignant solitary fibrous tumor involving the liver. World J Gastroenterol. 2013; 19(21): 3354-7. http://dx.doi.org/10.3748/wjg.v19.i21.3354 
[20] Novais P, Robles-Medranda C, Pannain VL, et al. Solitary fibrous liver tumor: Is surgical approach the best option? J Gastrointestin Liver Dis. 2010; 19: 81-4. PMid: 20361081.

[21] Morris R, McIntosh D, Helling T, et al. Solid fibrous tumor of the liver: a case in pregnancy. The Journal of Maternal-Fetal and Neonatal Medicine. 2012; 25(6): 866-8. PMid: 21827348. http: //dx.doi.org/10.3109/14767058.2011.596958

[22] Bongiovanni M, Viberti L, Giraudo G, et al. Solitary fibrous tumour of the adrenal gland associated with pregnancy. Virchows Arch. 2000; 437: 445-9. PMid: 11097372. http://dx.doi.org/10.1007/s 004280000268

[23] Das JK, Sharma AS, Deka ACh, et al. Solitary fibrous tumor of the orbit presenting in pregnancy. Indian Journal of Ophthalmology. 2009; 57(3): 238-40. PMid: 19384025. http://dx.doi.org/10. 4103/0301-4738.49405

[24] Peksa M, Bockowski M, Preis K. Solitary fibrous tumor of the retroperitoneum in pregnancy: case report. Ginek Pol. 2011; 82(5): 382-5. PMid: 21851039.

[25] Klemperer P, Rabin CB. Primary neoplasms of the pleura. A report of five cases. Arch Pathol. 1931; 11: 385-412. PMid: 1415270.

[26] Fletcher CDM, Bridge J, Hogendoorn P, et al. WHO Classification of Tumours of Soft Tissue and Bone. 2013; 4th ed:80-2.

[27] Fletcher CDM. The evolving classification of soft tissue tumours: an update based on the new 2013 WHO classification. Histopathology.
2014; 64(1): 2-11. PMid: 24164390. http://dx.doi.org/10.11 $11 /$ his. 12267

[28] Fama F, Le Bouc Y, Barrande G, et al. Solitary fibrous tumour of the liver with IGF-II-related hypoglycaemia. A case report. Langenbecks Arch Surg. 2008; 393: 611-6. PMid: 18418627. http: //dx.doi.org/10.1007/s00423-008-0329-z

[29] Benaglia L, Cardellicchio L, Filippi F, et al. The rapid growth of fibroids during early pregnancy. PLoS ONE. 2014; (9)1: e85933. http://dx.doi.org/10.1371/journal.pone.0085933

[30] De Bree E, Dimitriadis E, Giannikaki E, et al. A giant pregnancyassociated intra-abdominal desmoid tumor: not necessarily a contraindication for subsequent pregnancy. World Journal of Surgical Oncology. 2013; 11: 277-82. http://dx.doi.org/10.1186/147 7-7819-11-277

[31] Bongiovanni M, Viberti L, Pecchioni C, et al. Steroid hormone receptor in pleural solitary fibrous tumors and CD34+ progenitor stromal cells. The Journal of Pathology. 2002; 198(2): 252-7. PMid: 12237886. http://dx.doi.org/10.1002/path.1195

[32] Chmielecki J, Crago AM, Rosenberg M, et al. Whole-exome sequencing identifies a recurrent NAB2-STAT6 fusion in solitary fibrous tumors. Nat Genet. 2013; 45: 131-2. http://dx.doi.org/10.10 38/ng. 2522

[33] Yoshida A, Tsuta K, Ohno M, et al. STAT6 Immunohistochemistry Is Helpful in the Diagnosis of Solitary Fibrous Tumors. Am J Surg Pathol. 2014; 38(4): 552-9. PMid: 24625420. http://dx.doi.o rg/10.1097/PAS . 0000000000000137 